\title{
ADAPTIVE CLASSROOM BERBASIS IOT (INTERNET OF THINGS), SAKLAR LAMPU BERDASARKAN KEBERADAAN SESEORANG DAN INTENSITAS CAHAYA
}

\author{
(Adaptive Classroom Based on Internet of Things, Light Switches Based on Someone's \\ Existence and Light Intensity)
}

\author{
Hendra Oji Pratama, I Gde Putu Wirarama Wedashwara Wirawan", Ariyan Zubaidi \\ Program Studi Teknik Informatika FT-UNRAM \\ Jl. Majapahit 62, Mataram, Lombok NTB, INDONESIA \\ Email: hendraojipratama@gmail.com, [wirarama, zubaidi13]@unram.ac.id
}

\begin{abstract}
A switch is a device for disconnecting or connecting electricity, usually used on lights. The Informatics Engineering Study Program (PSTI) of the Faculty of Engineering of the University of Mataram (UNRAM) has several classrooms with light switches controlled by manual switches. Problems occur when classroom users do not turn off class lights after use or when the room has sufficient lighting from outside. The solution is by implementing an Internet of Things (IoT) based automatic control system that uses several sensors as a trigger switch. The monitoring system created can display light intensity data, motion status, and lamp status in real time obtained from the electronic circuit of the system via the MQTT protocol. Based on the test scheme carried out, the system created can perform lamp management based on the conditions received. MOS testing produces value 4.58 from scale 5 shows that the system is feasible to use.
\end{abstract}

Key words: Internet of Things, MQTT, Light Switch Control, Light Dependent Resistor, Passive Infra Red.

*Penulis Korespondensi

\section{Pendahuluan}

Saklar merupakan sebuah perangkat yang menghubungkan aliran listrik. Salah satu contoh perangkat elektronik yang menggunakan saklar adalah lampu. Pada umumnya pengendalian saklar lampu yang dijumpai masih banyak yang dioperasikan tanpa otomatisasi yang berpotensi menyebabkan pemborosan konsumsi listrik. Sebagai contoh ketika seseorang lupa untuk mematikan lampu saat tidak diperlukan yang mengakibatkan penggunaan lampu tidak efisien [1].

Teknik Informatika sebagai salah satu program studi dari Fakultas Teknik yang berada di lingkungan Universitas Mataram (UNRAM) memiliki beberapa ruang kelas yang sudah terinstalasi berbagai macam perangkat elektronik, salah satunya adalah lampu. Pengendalian saklar lampu di setiap kelas masih dilakukan secara manual, misalnya saklar lampu akan dihidupkan saat ruangan tidak memiliki cukup cahaya, kemudian jika ruangan memiliki penerangan yang cukup dari luar (cahaya matahari), perlu mematikan saklar lampu untuk menghindari penggunaan lampu yang tidak efisien. Namun, menjadi masalah ketika pengguna ruang kelas tidak mematikan lampu setelah kelas selesai digunakan atau saat ruangan memiliki penerangan yang cukup dari luar.

Masalah pengendalian saklar lampu pada PSTI UNRAM dapat diminimalisir dengan menerapkan sistem pengendalian secara otomatis yang menggunakan beberapa sensor sebagai pemicu saklar dengan memanfaatkan konsep Internet of Things (IoT). Implementasi loT memungkinkan berbagai perangkat yang beroperasi dengan tegangan listrik khususnya arus searah (DC) terhubung dengan jaringan komunikasi internet [2][3]. IoT berkomunikasi melalui jaringan internet untuk berbagai keperluan seperti sistem kendali melalui antar muka web, yang menghubungan mesin ke mesin [4].

Sejalan dengan pengertian maupun cara kerja dari IoT, sistem saklar lampu pada PSTI UNRAM dapat menerapkan konsep tersebut dengan memanfaatkan koneksi internet yang telah terinstalasi. Dengan begitu, penggunaan lampu dapat dipantau dengan sistem monitoring yang terhubung secara langsung dengan sistem saklar baik itu berupa data realtime maupun data yang tercatat sebelumnya.

Berdasarkan hal-hal tersebut pada penelitian ini akan dibangun sebuah sistem saklar lampu pada ruang kelas berdasarkan keberadaan seseorang dan intensitas cahaya yang dapat dipantau melalui sistem monitoring 
dengan memanfaatkan konsep loT untuk membantu PSTI UNRAM dalam memanajemen lampu agar penggunaan lampu lebih efisien dan mengurangi human error.

\section{TinjauAn PUSTAKA}

Penelitian mengenai pengendalian saklar lampu sudah pernah dilakukan oleh beberapa peneliti dan kedepan dijadikan acuan referensi bagi penelitian yang dilakukan.

Penelitian mengenai sistem penyalaan lampu otomatis yang dilakukan oleh Imam Marzuki pada tahun 2019 dengan merancang sebuah sistem automasi yang bertujuan menghemat penggunaan listrik pada lampu. Perancangan sistem dibagi menjadi dua sensor yang terdiri dari sensor Passive Infra Red (PIR) dan sensor Light Dependent Resistor (LDR). PIR bekerja dengan menembakkan sinar infrared secara acak untuk mendeteksi pergerakan dalam ruangan. LDR bekerja mengkonversi intensitas cahaya menjadi arus kecil dimana arus tersebut dapat dikalibrasikan sebagai kadar cahaya. Hasil dari pengujian sistem didapat bahwa sensor PIR bekerja dengan baik berkisar \pm 2 menit setelah alat diaktifkan. Jika mendeteksi gerakan manusia, maka lampu akan menyala dan sensor LDR akan mengukur nilai intensitas cahaya secara terus menerus yang jika nilai dari intensitas cahaya melebihi batas yang diprogram maka lampu akan mati dan sebaliknya [5][6].

Persamaan pada penelitian mengenai penyalaan lampu tersebut kesamaannya ada pada penggunaan sensor PIR dan LDR. Untuk perbedaannya, pada penelitian yang akan dilakukan dengan menambahkan penggunaan mikrokontroler WeMos D1 (R2) yang menerapkan konsep loT dan dilakukan pencatatan data penggunaan lampu yang dapat dimonitor dengan sistem berbasis web.

Penelitian tentang kendali lampu dengan protokol MQTT oleh Noor Fitria Azzahra pada tahun 2018, peneliti bertujuan untuk membuat sebuah saklar yang dapat dikendalikan dari jarak jauh dalam skala rumah tangga. Alat yang digunakan adalah Arduino promini, ESP01 dengan Library Wifimanager, menggunakan protokol MQTT dan kode yang dibuat untuk aplikasi IoT sistem kendali saklar menggunakan NodeJs dan Jason untuk Webservice. Penelitian ini menggunakan dua kondisi berbeda untuk alat yang digunakan, yaitu satu diletakkan di jaringan yang ramai dan satu alat lainnya diletakkan pada jaringan yang tidak ramai. Tujuannya untuk mengetahui seberapa ketahanan alat terhadap kedua kondisi jaringan tersebut. Dari hasil perancangan purwarupa loT sistem kendali lampu dapat disimpulkan bahwa protokol MQTT dapat digunakan untuk membuat sistem IoT namun Library Wifimanager tidak mampu menangani perpindahan access point wifi [4][7].

Persamaan penelitian kendali lampu dengan protokol MQTT dengan penelitian yang akan dilakukan terdapat pada penggunaan protokol MQTT. Untuk perbedaannya, pada penelitian yang akan dilakukan menggunakan mikrokontroler WeMos D1 (R2) dan menggunakan sensor PIR dan LDR yang berperan dalam penentuan kondisi untuk memanajemen lampu untuk melakukan pencatatan data yang dapat dimonitor dengan sistem berbasis web.

Sementara itu, pada 2013 telah dilakukan penelitian mengenai penerangan rumah otomatis oleh Julpan Welman. Peneliti merancang prototype penerangan rumah berbasis mikrokontroler ATMega8535 dengan menggunakan sensor PIR, LDR dan Time Delay Relay (Timer) sebagai pengatur waktu. Kesimpulan dari hasil perancangan dan pengamatan yaitu peneliti berhasil merancang prototype penerangan rumah pada masing-masing ruangan yang jika pada ruangan tersebut terdapat seseorang dan dalam kondisi mendung maka lampu akan hidup dan jika cuaca cerah maka lampu akan mati. Namun pada waktu tertentu sesuai dengan waktu yang diatur pada masing-masing ruangan lampu dapat hidup atau mati dengan sendirinya tanpa menghiraukan sensor LDR atau PIR [8][9].

Penelitian penerangan rumah otomatis dengan juga sama-sama terdapat penggunaan sensor PIR dan LDR. Untuk perbedaannya, pada penelitian ini menggunakan mikrokontroler WeMos D1 (R2) yang menerapkan konsep loT dan dilakukan pencatatan data yang dapat dimonitor dengan sistem berbasis web.

\section{Metode Penelitian}

\subsection{Analisis Kebutuhan Sistem}

Analisis kebutuhan sistem akan dilakukan terhadap kebutuhan dari sistem Adaptive Classroom Berbasis loT, Saklar Lampu Berdasarkan Keberadaan Seseorang dan Intensitas Cahaya yang akan dibangun, meliputi kebutuhan alat dan bahan yang diperlukan dan anggaran biaya dalam pembuatan sistem.

\section{A.1. Perangkat Keras}

- Laptop/PC untuk aktivitas pembuatan code aplikasi

\section{A.2. Perangkat Lunak}

- Sistem operasi Windows 10

- Arduino IDE versi 1.8 .10 sebagai code editor untuk mikrokontroler 
- Sublime Text versi 3.2.2 sebagai code editor untuk web

Browser untuk mengakses halaman web

A.3. Bahan Penelitian

- 1 buah mikrokontroler WeMos D1 (R2)

- 1 set kabel jumper

- 1 buah sensor PIR HC-SR501 sebagai pendeteksi keberadaan seseorang

- 1 buah sensor LDR GL5528 sebagai pengukur intensitas cahaya

- 2 buah relay 5VDC JQC-3FF-S-Z sebagai pengganti saklar manual

- 1 buah adapter untuk menghubungkan mikrokontroler dengan sumber daya

\section{A.4. Perencanaan Biaya}

Dari analisis kebutuhan alat dan bahan penelitian, anggaran dalam melakukan penelitian ini disesuaikan dengan kebutuhan dari alat dan bahan. Perencanaan biaya dari bahan yang dibutuhkan dapat dilihat pada Tabel I.

TABel I. PerencanaAn biaya

\begin{tabular}{|c|l|l|r|}
\hline No. & \multicolumn{1}{|c|}{ Nama Alat } & Jumlah & \multicolumn{1}{c|}{ Harga } \\
\hline 1 & WeMos D1 (R2) & 1 buah & Rp. 100.000 \\
\hline 2 & Sensor LDR & 1 buah & Rp. 5.000 \\
\hline 3 & Sensor PIR & 1 buah & Rp. 15.000 \\
\hline 4 & Relay & 2 buah & Rp. 20.000 \\
\hline 5 & Kabel Jumper & 1 set & Rp. 40.000 \\
\hline 6 & Adapter & 1 buah & Rp. 20.000 \\
\hline \multicolumn{3}{|c|}{ Jumlah } & Rp. 200.000 \\
\hline
\end{tabular}

\subsection{Perancangan Perangkat Keras}

Perancangan perangkat keras dilakukan terhadap arsitektur sistem dan gambaran rangkaian elektronika dari sistem yang akan dibangun. Perancangan ini terdiri dari perancangan arsitektur sistem dan perancangan elektronika sistem.

\subsubsection{Perancangan Arsitektur Sistem}

Gambaran dari arsitektur sistem Adaptive Classroom Berbasis loT, Saklar Lampu Berdasarkan Keberadaan Seseorang dan Intensitas Cahaya yang akan dibangun dapat dilihat pada Gambar 1.

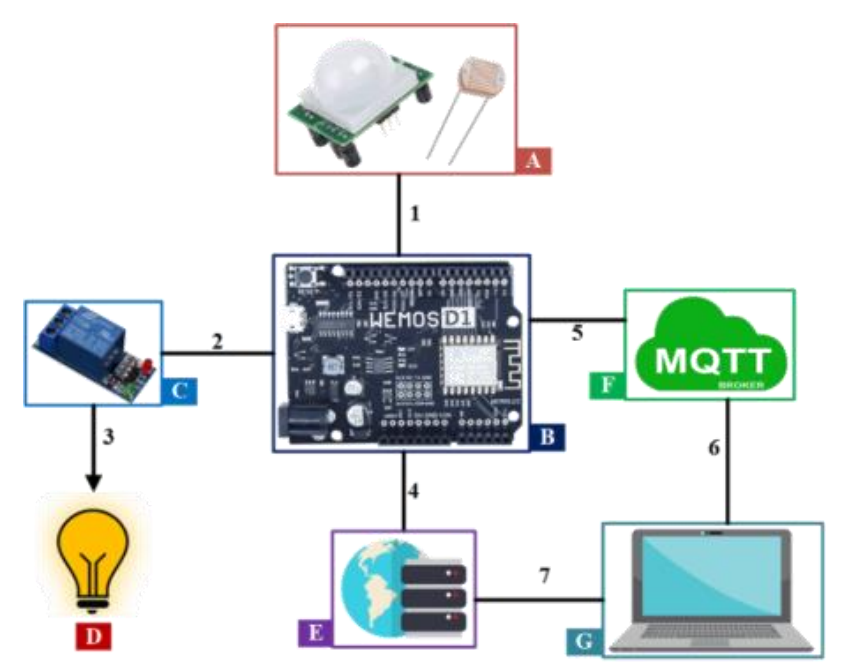

Gambar 1. Perancangan arsitektur sistem.

Berikut merupakan penjelasan arsitektur sistem pada Gambar 1 :

- Sensor (A) yang digunakan yakni PIR untuk mendeteksi pancaran sinar inframerah yang dihasilkan oleh gerakan manusia dan LDR digunakan untuk mengetahui tingkat intensitas dari cahaya yang ada pada ruangan.

- Mikrokontroler (B) digunakan sebagai tempat terhubungnya sensor dan relay yang memiliki beban library ESP8266WiFi untuk dapat terkoneksi dengan internet, library PubSubClient yang digunakan untuk dapat terhubung dengan server broker sebagai client dan juga library ESP8266HTTPClient yang digunakan untuk dapat mengakses layanan web.

- Relay (C) berperan sebagai pengganti saklar yang akan memutus atau menghubungkan aliran listrik menuju lampu.

- Lampu (D) ini merupakan perangkat yang akan diatur oleh sistem.

- Web Server (E) digunakan untuk menyimpan halaman web dan tempat menyimpan hasil pencatatan data.

- Sever broker (F) merupakan server yang akan dituju oleh client dalam penyampaian data dimana pengiriman datanya menggunakan protokol MQTT.

- Laptop/PC (G) adalah perangkat yang dapat digunakan untuk mengakses sistem monitoring berbasis web.

Berikut merupakan penjelasan dari hubungan antar perangkat yang terdapat pada Gambar 1 :

- Hasil dari pembacaan dari sensor (A) akan diterima oleh mikrokontroler (B) untuk dilakukan pengolahan dalam menentukan kondisi saklar lampu. 
- Mikrokontroler akan melakukan perubahan status terhadap relay (C) sesuai dengan hasil penentuan kondisi yang akan diteruskan ke lampu (D).

- Mikrokontroler meneruskan data hasil penentuan kondisi relay dengan mengakses layanan web untuk dilakukan penyimpanan data pada web server (E).

- Mikrokontroler juga meneruskan data hasil penentuan kondisi relay menuju server broker (F) agar setiap client yang terhubung dapat menerima pesan yang dikirim oleh mikrokontroler secara langsung.

- Laptop/PC (G) melakukan akses terhadap sistem web yang tersimpan pada web server dan juga dapat menerima data dari server broker.

\subsubsection{Perancangan Elektronika Sistem}

Gambaran dari rangkaian elektronika sistem Adaptive Classroom Berbasis IoT, Saklar Lampu Berdasarkan Keberadaan Seseorang dan Intensitas Cahaya yang akan dibangun dapat dilihat pada Gambar 2.

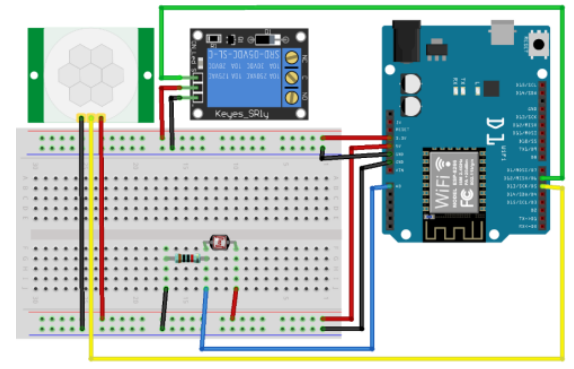

Gambar 2. Rangkaian elektronika sistem.

Berikut merupakan penjelasan dari masing-masing rangkaian yang terdapat pada Gambar 2 :

- Sensor PIR yang digunakan memiliki 3 buah pin yang terhubung dengan mikrokontroler. Pin pertama (kabel merah) dihubungkan dengan pin 5V pada mikrokontroler. Pin kedua (kabel kuning) dihubungkan dengan pin digital (D5). Pin terakhir (kabel hitam) dihubungkan dengan pin GND pada mikrokontroler.

- Sensor LDR mempunyai dua kaki yang dibentuk menjadi 3 pin dengan menghubungkan salah satunya pada sebuah resistor. Pin pertama (yang tidak terhubung dengan resistor) dihubungkan dengan pin $5 \mathrm{~V}$ pada mikrokontroler (kabel merah). Pin kedua (kaki yang terhubung dengan resistor) dihubungkan dengan pin AO pada mikrokontroler (kabel biru). Untuk pin terakhir merupakan bagian dari kaki resistor yang tidak terhubung dengan kaki sensor LDR dihubungkan dengan pin GND pada mikrokontroler (kabel hitam).
- Relay memiliki 3 buah pin yang terhubung pada mikrokontroler, pin pertama (kabel hitam) dihubungkan dengan pin GND pada mikrokontroler. Pin kedua (kabel merah) dihubungkan dengan pin 3V pada mikrokontroler. Dan pin yang terakhir (kabel hijau) dihubungkan dengan pin D6 dengan pada mikrokontroler.

\subsection{Perancangan Perangkat Lunak}

Pada tahap perancangan perangkat lunak, dilakukan perancangan web untuk sistem yang akan dibangun. Selain merancang web, pada tahap ini juga akan dilakukan perancangan arsitektur protokol sistem.

\section{a. Perancangan Sistem Monitoring Berbasis Web}

Perancangan Sistem Monitoring berbasis web terdiri dari rancangan use case diagram. Use case diagram yang telah dirancang pada sistem monitoring Adaptive Classroom berbasis IOT Saklar Lampu Berdasarkan Sensor Keberadaan Seseorang dan Intensitas Cahaya ditunjukkan pada Gambar 3.

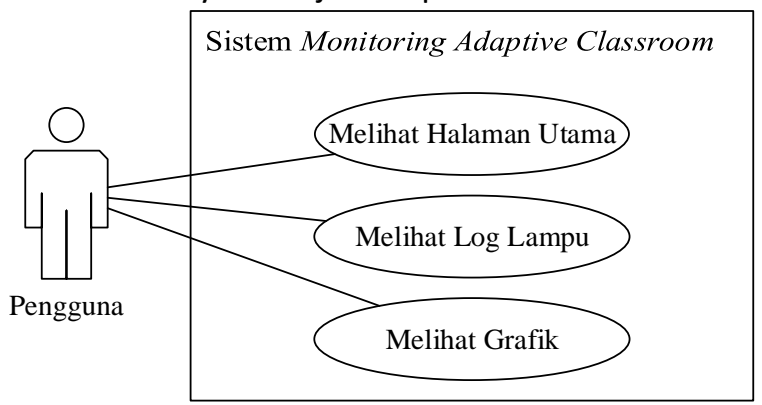

Gambar 3. Use case diagram sistem.

Dilihat dari Gambar 3, sistem ini terdapat satu aktor yaitu pengguna yang dapat melihat halaman utama dari sistem, melihat log lampu dan melihat grafik dari penggunaan lampu. Aktor pengguna yang dimaksud masih bersifat umum dalam arti siapa saja bisa melakukan akses terhadap sistem web ini dikarenakan sistem ini masih berupa prototype. Namun ke depannya diharapkan data lampu yang tersimpan di web ini dapat digunakan oleh staf di bagian akademik untuk mengetahui penggunaan lampu yang ada pada setiap ruang kelas.

\section{b. Perancangan Arsitektur Protokol Sistem}

Perancangan arsitektur protokol sistem merupakan perancangan komunikasi data yang menggunakan protokol MQTT dan HTTP. Berikut merupakan arsitektur protokol pada sistem monitoring Adaptive Classroom berbasis loT Saklar Lampu Berdasarkan Sensor Keberadaan Seseorang dan Intensitas Cahaya dapat dilihat pada Gambar 4. 


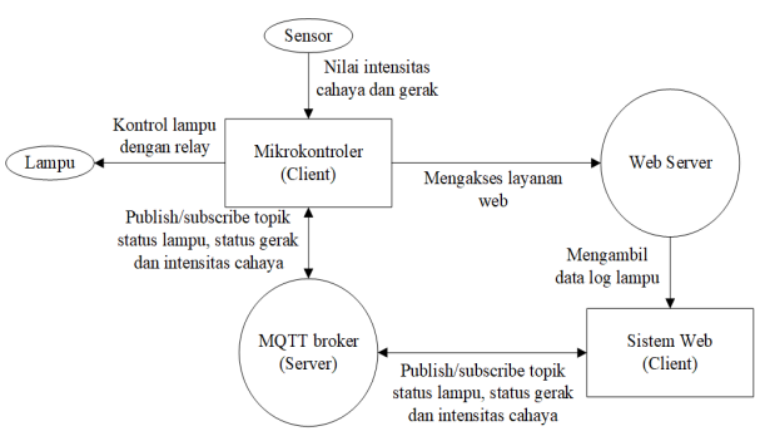

Gambar 4. Rancangan arsitektur protokol sistem.

\section{c. Skema Pengujian dan Evaluasi Sistem}

Proses pengujian sistem Adaptive Classroom Berbasis loT, Saklar Lampu Berdasarkan Keberadaan Seseorang dan Intensitas Cahaya dilakukan di ruang D102 PSTI UNRAM. Pengujian dilakukan terhadap perangkat keras dan sistem web dengan melakukan simulasi pada ruangan yang melibatkan beberapa orang responden dengan detail pengujian perangkat yang terdapat pada Tabel II. Berikut detail pengujian yang dilakukan pada perangkat dapat dilihat pada Tabel II.

TABEL II. DETAIL PENGUJIAN PERANGKAT

\begin{tabular}{|c|c|c|c|l|}
\hline No. & $\begin{array}{c}\text { LDR } \\
\text { (Cahaya } \\
\text { Ruangan } \\
(\text { Iux)) }\end{array}$ & $\begin{array}{c}\text { PIR } \\
\text { (Gerakan) }\end{array}$ & $\begin{array}{c}\text { Relay } \\
\text { (Status } \\
\text { Lampu) }\end{array}$ & Keterangan \\
\hline 1 & $\begin{array}{c}\text { Cukup } \\
(250-350)\end{array}$ & Ada & NO (Mati) & Valid/Invalid \\
\hline 2 & $\begin{array}{c}\text { Cukup } \\
(250-350)\end{array}$ & Tidak Ada & NO (Mati) & Valid/Invalid \\
\hline 3 & $\begin{array}{c}\text { Kurang } \\
(<250)\end{array}$ & Ada & NC (Hidup) & Valid/Invalid \\
\hline 4 & $\begin{array}{c}\text { Kurang } \\
(<250)\end{array}$ & Tidak Ada & NO (Mati) & Valid/Invalid \\
\hline 5 & $\begin{array}{c}\text { Lebih } \\
(>350)\end{array}$ & Ada & NO (Mati) & Valid/Invalid \\
\hline 6 & $\begin{array}{c}\text { Lebih } \\
(>350)\end{array}$ & Tidak Ada & NO (Mati) & Valid/Invalid \\
\hline
\end{tabular}

\section{HASIL dAN PEMBaHASAN}

Sistem monitoring Adaptive Classroom berbasis IoT Saklar Lampu Berdasarkan Sensor Keberadaan Seseorang dan Intensitas Cahaya berbasis web telah dibuat sesuai dengan perancangan yang telah dibuat sebelumnya. Bab ini akan membahas hasil yang telh dicapai oleh hasil rancang bangun serta evaluasi yang telah dilakukan untuk mengukur kinerjanya.

\subsection{Realisasi Penyusunan Perangkat Keras Sistem}

Perangkat keras yang sudah di rancang bangun dari sistem Adaptive Classroom berbasis loT Saklar Lampu Berdasarkan Sensor Keberadaan Seseorang dan Intensitas Cahaya mengacu pada rancangan perangkat keras yang telah dibuat sebelumnya ditunjukkan oleh Gambar 5.

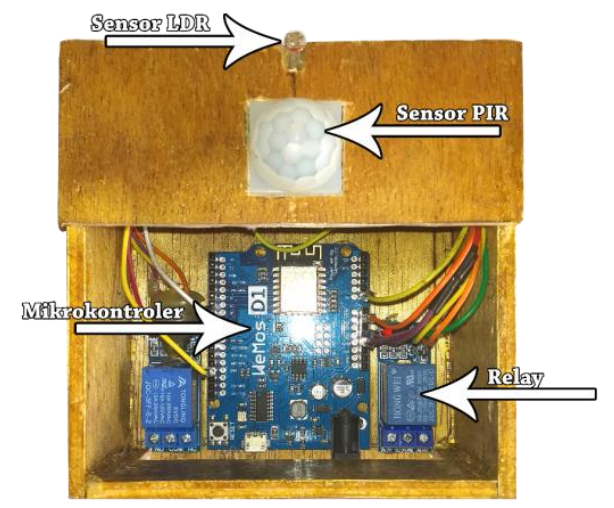

Gambar 5. Realisasi perangkat keras.

Berikut merupakan penempatan alat yang dipasang pada ruang kelas D1-02 PSTI UNRAM dapat dilihat pada Gambar 6. Rangkaian alat dipasang pada dinding ruang kelas dekat dengan saklar lampu.

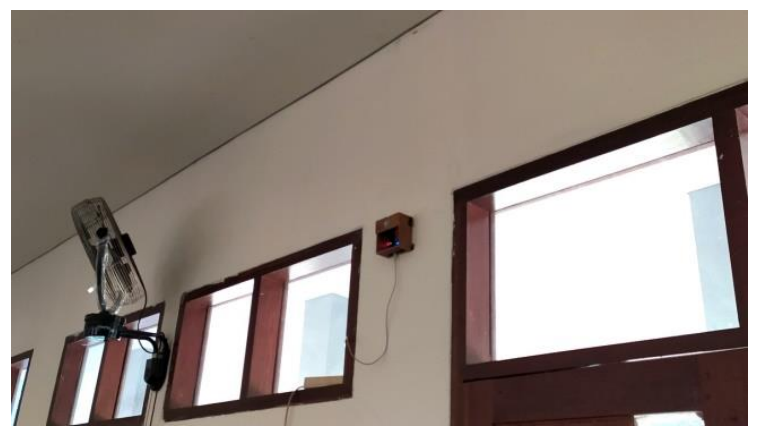

Gambar 6. Penempatan alat pada ruangan.

\subsection{Realisasi Pengembangan Web}

Pembangunan web ini menggunakan kerangka kerja Codelgniter yang berbasis bahasa pemrograman PHP. Folder Codelgniter sistem ditunjukkan oleh Gambar 7.

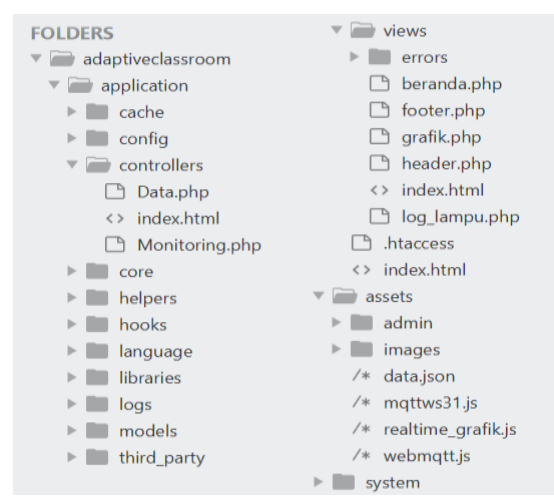

Gambar 7. Realisasi pengembangan web. 


\subsection{Realisasi Interface Sistem}

Berikut ini merupakan realisasi dari antarmuka sistem web Adaptive Classroom berbasis IoT Saklar Lampu Berdasarkan Sensor Keberadaan Seseorang dan Intensitas Cahaya. Sistem web yang dibangun terdiri dari halaman utama, halaman log lampu dan halaman grafik penggunaan lampu. Realisasi halaman utama sistem web ditunjukkan Gambar 8.

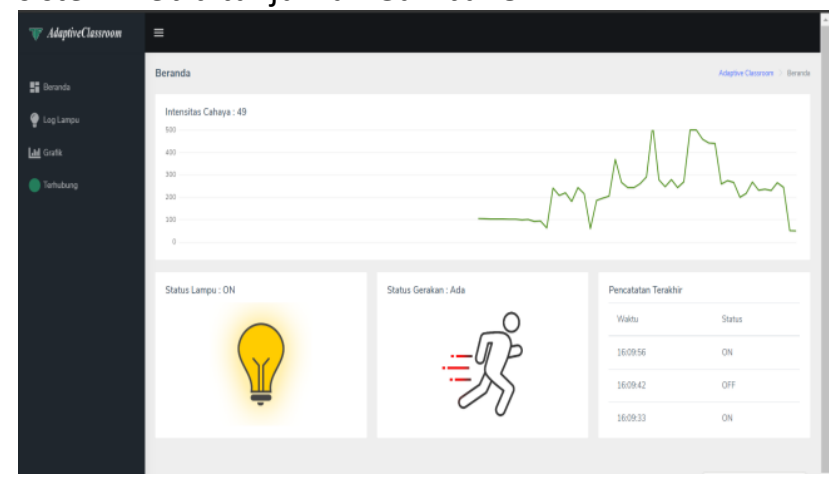

Gambar 8. Realisasi antarmuka sistem halaman utama.

Adapun realisasi sistem web pada halaman log lampu berisi data catatan penggunaan lampu harian. Tampilan halaman log lampu ditunjukkan Gambar 9.

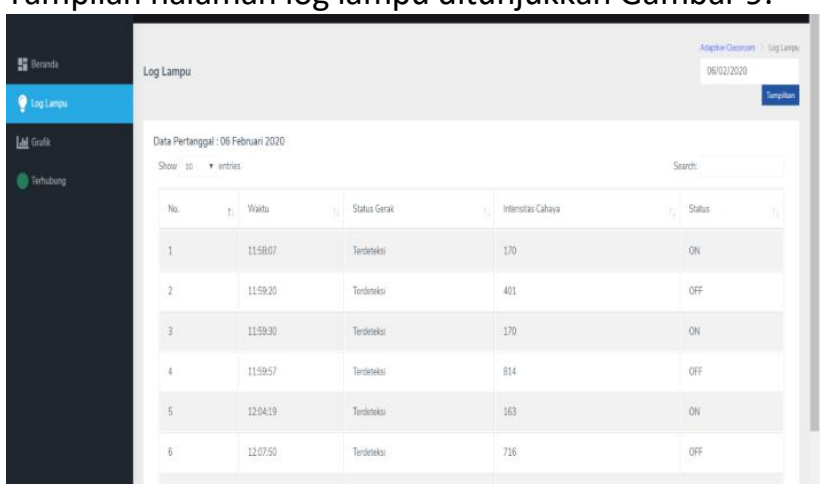

Gambar 9. Realisasi antarmuka sistem halaman log lampu.

Adapun realisasi sistem web pada halaman grafik berisi data catatan penggunaan lampu harian dalam bentuk grafik. Tampilan halaman log lampu dapat dilihat pada Gambar 10.

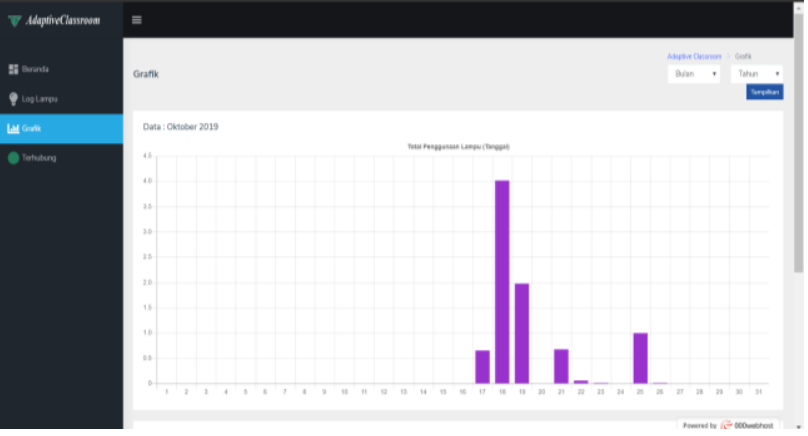

Gambar 10. Realisasi antarmuka sistem halaman grafik.

\subsection{Pengujian Sistem}

Pengujian perangkat lunak sistem dilakukan dengan menguji fungsi masing-masing komponen perangkat keras sistem dan fungsi masing-masing menu dari sistem web. Metode yang digunakan dalam pengujian sistem ini adalah metode black box. Kemudian untuk pengujian keseluruhan sistem akan dilakukan di ruang D1-02 PSTI FT UNRAM.

Proses pengujian perangkat keras sistem saklar lampu ini dilakukan dengan menguji perangkat keras dari segi fungsionalnya saja. Pengujian perangkat keras ini digunakan untuk mengetahui apakah fungsi dan keluaran dari perangkat keras yang digunakan sudah sesuai atau tidak.

\subsubsection{Hasil Pengujian Sensor LDR}

Sensor LDR diuji dengan melakukan penutupan sensor oleh benda yang memiliki tingkat variasi transparansi seperti pada Gambar 11. Pengujian ini dilakukan untuk mengetahui tingkat sensitivitas sensor yang telah dihubungkan dalam rangkaian loT terhadap cahaya.

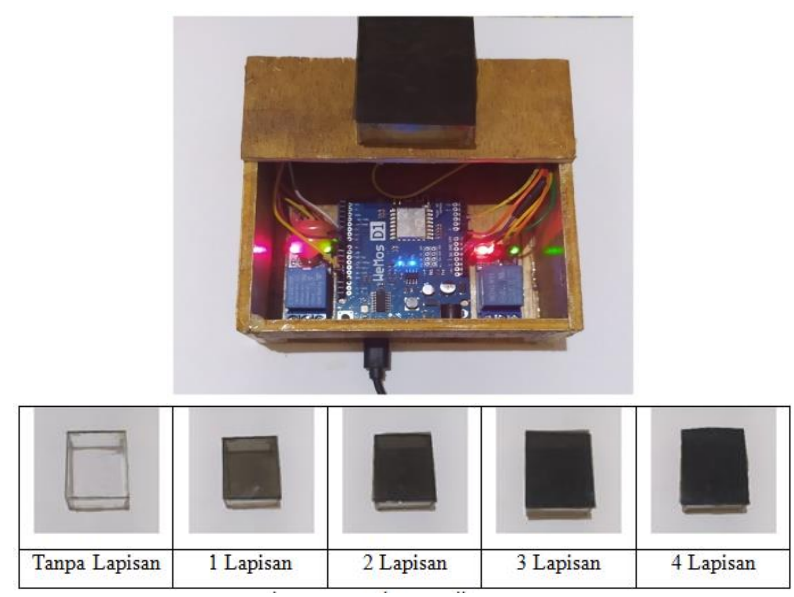

Gambar 11. Pengujian sensor LDR. 
Hasil dari pengujian sensor LDR disajikan dalam bentuk tabel yang terdiri dari kondisi sensor beserta nilai intensitas cahaya yang didapat. Adapun hasil pengujian sensor LDR dapat dilihat pada Tabel III.

TABEL III. HASIL PENGUJIAN SENSOR LDR

\begin{tabular}{|c|c|c|}
\hline No. & Kondisi & $\begin{array}{c}\text { Nilai } \\
\text { Intensitas } \\
\text { (lux) }\end{array}$ \\
\hline 1 & Tanpa ditutupi benda & 165 \\
\hline 2 & $\begin{array}{c}\text { Ditutupi benda 1 (tanpa } \\
\text { lapisan) }\end{array}$ & 155 \\
\hline 3 & $\begin{array}{c}\text { Ditutupi benda 2 (1 } \\
\text { lapisan) }\end{array}$ & 80 \\
\hline 4 & $\begin{array}{c}\text { Ditutupi benda 3 (2 } \\
\text { lapisan) }\end{array}$ & 55 \\
\hline 5 & $\begin{array}{c}\text { Ditutupi benda 4 (3 } \\
\text { lapisan) }\end{array}$ & 30 \\
\hline 6 & $\begin{array}{c}\text { Ditutupi benda 5 (4 } \\
\text { lapisan) }\end{array}$ \\
\hline
\end{tabular}

Dari Tabel III dapat dilihat bahwa sensor LDR bekerja cukup baik, yakni semakin banyak lapisan yang menutupi benda (menghasilkan gelap) maka semakin kecil juga nilai dari intensitas cahaya yang di terima oleh sensor.

\subsubsection{Pengujian Sensor PIR}

Pengujian sensor PIR dilakukan pada ruang D1-02 yang memiliki panjang 11 meter dan lebar 7 meter. Pengujian ini dilakukan untuk mengetahui kinerja dari sensor yang terdapat pada rangkaian perangkat keras sistem apakah dapat bekerja dengan baik atau tidak dalam mendeteksi keberadaan seseorang dalam jarak dan sudut tertentu. Dokumentasi pengujian sistem dapat dilihat pada Gambar 12.

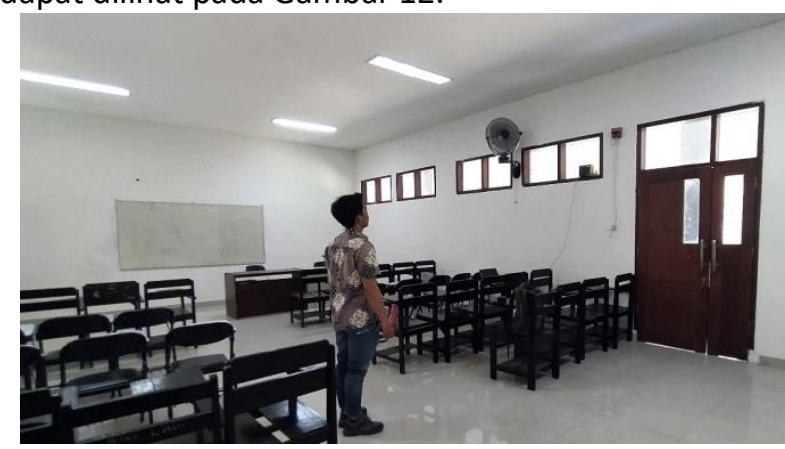

Gambar 12. Pengujian sensor PIR.

Berikut ini merupakan hasil dari pengujian sensor PIR yang dapat dilihat pada Tabel IV.

TABEL IV. HASIL PENGUJIAN SENSOR PIR

\begin{tabular}{|c|c|c|c|c|c|c|c|}
\hline \multirow{2}{*}{ No. } & \multirow{2}{*}{ Sudut } & \multicolumn{5}{|c|}{ Jarak jangkauan sensor } \\
\cline { 3 - 8 } & & $\mathbf{1 m}$ & $\mathbf{2 m}$ & $\mathbf{3 m}$ & $\mathbf{4 m}$ & $\mathbf{5 m}$ & $\mathbf{6 m}$ \\
\hline 1 & $0^{\circ}$ & $\mathrm{V}$ & $\mathrm{V}$ & $\mathrm{V}$ & $\mathrm{V}$ & $\mathrm{V}$ & $\mathrm{X}$ \\
\hline 2 & $30^{\circ}$ & $\mathrm{V}$ & $\mathrm{V}$ & $\mathrm{V}$ & $\mathrm{V}$ & $\mathrm{V}$ & $\mathrm{X}$ \\
\hline 3 & $60^{\circ}$ & $\mathrm{V}$ & $\mathrm{V}$ & $\mathrm{V}$ & $\mathrm{V}$ & $\mathrm{V}$ & $\mathrm{X}$ \\
\hline 4 & $80^{\circ}$ & $\mathrm{X}$ & $\mathrm{X}$ & $\mathrm{X}$ & $\mathrm{X}$ & $\mathrm{X}$ & $\mathrm{X}$ \\
\hline
\end{tabular}

Keterangan : $\quad V=$ Terdeteksi

$\mathrm{X}=$ Tidak terdeteksi

Dari hasil pengujian yang dapat dilihat pada Tabel 4, diketahui bahwa sensor dapat mendeteksi gerakan pada rentang jarak optimal yaitu 5 meter dan sudut yang dapat dijangkau yaitu $60^{\circ}$.

\subsubsection{Pengujian Relay}

Pengujian relay pada perangkat dilakukan untuk mengetahui apakah berfungsi dengan baik atau tidak dalam menghubungkan atau memutuskan aliran listrik. Pengujian relay dapat dilihat pada Gambar 13.

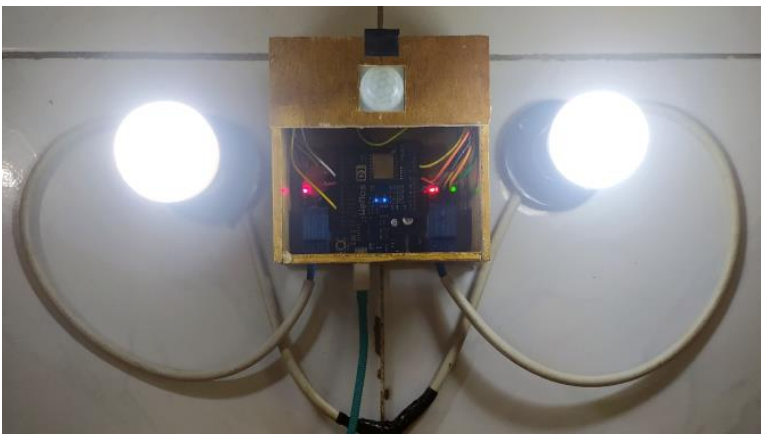

Gambar 13. Pengujian relay.

Berikut merupakan tabel hasil dari pengujian relay dapat dilihat pada Tabel V.

TABEL V. HASIL PENGUJIAN RELAY

\begin{tabular}{|c|c|c|c|}
\hline No. & $\begin{array}{c}\text { Kondisi } \\
\text { Relay }\end{array}$ & $\begin{array}{c}\text { Status } \\
\text { Relay }\end{array}$ & $\begin{array}{c}\text { Kondisi } \\
\text { Lampu }\end{array}$ \\
\hline 1 & Low & Hidup & Menyala \\
\hline 2 & High & Mati & Padam \\
\hline
\end{tabular}

Dari Tabel 5 dapat dilihat bahwa saat relay di kondisikan dengan nilai "Low" atau relay dalam keadaan hidup, kondisi lampu yang didapat yaitu dalam keadaan menyala sedangkan saat relay dikondisikan dengan nilai "High" atau relay dalam keadaan mati, kondisi lampu yang didapat yaitu dalam keadaan padam. Dari hasil pengujian tersebut dapat disimpulkan bahwa relay dapat bekerja dengan baik sesuai dengan apa yang diharapkan. 


\subsubsection{Pengujian Sistem Web}

Proses pengujian web sistem saklar lampu ini diuji dengan metode black box yang menghubungkan fungsional masing-masing. Pengujian ini dilakukan untuk melihat hasil dari fungsi atau fitur yang ada di dalam web. Berikut merupakan hasil pengujian fungsi dari sistem web yang telah dilakukan.

\section{a. Pengujian Fungsi Menu Log Lampu}

Pengujian fungsi menu log lampu ini dilakukan untuk mengetahui apakah fungsi ini sudah berjalan sesuai dengan yang diinginkan saat diakses oleh pengguna. Berikut hasil pengujian dari fungsi menu log lampu dapat dilihat pada Tabel VI.

TABEL VI. HASIL PENGUJIAN FUNGSI MENU LOG LAMPU

\begin{tabular}{|c|c|c|c|c|}
\hline No. & $\begin{array}{c}\text { Skenario } \\
\text { Pengujian }\end{array}$ & $\begin{array}{l}\text { Hasil Yang } \\
\text { Diharapkan }\end{array}$ & $\begin{array}{c}\text { Hasil } \\
\text { Pengujian }\end{array}$ & Kesimpulan \\
\hline 1 & $\begin{array}{c}\text { Form pilih } \\
\text { tanggal diisi } \\
\text { dengan } \\
\text { tanggal yang } \\
\text { tidak } \\
\text { memiliki data } \\
\text { diberkas } \\
\text { penyimpanan }\end{array}$ & $\begin{array}{c}\text { Menampilkan } \\
\text { data kosong } \\
\text { pada tabel } \\
\text { log lampu }\end{array}$ & Sesuai & Valid \\
\hline 2 & $\begin{array}{c}\text { Form pilih } \\
\text { tanggal diisi } \\
\text { dengan } \\
\text { tanggal yang } \\
\text { memiliki data } \\
\text { diberkas } \\
\text { penyimpanan }\end{array}$ & $\begin{array}{c}\text { Menampilkan } \\
\text { data pada } \\
\text { tabel log } \\
\text { lampu }\end{array}$ & Sesuai & Valid \\
\hline
\end{tabular}

Berdasarkan hasil pengujian yang dilakukan dapat disimpulkan bahwa fungsi menu log lampu ini berjalan dengan baik sesuai dengan hasil yang diharapkan.

\section{b. Pengujian Fungsi Grafik}

Pengujian fungsi menu grafik ini dilakukan untuk mengetahui apakah fungsi ini sudah berjalan dengan yang diinginkan saat diakses oleh pengguna. Hasil pengujian dari fungsi menu grafik dapat dilihat pada Tabel VII. Melalui hasil pengujian dapat dievaluasi bahwa fungsional menu grafik ini berfungsi sesuai fungsional yang diharapkan oleh tahap perancangan.

\section{c. Hasil Pengujian Fungsi Keseluruhan Sistem}

Pada tahap ini dilakukan skenario pengujian pada perangkat yang telah terinstalasi pada ruang D1-02 PSTI UNRAM untuk menguji fungsionalitas sistem yang telah dirancang bangun. Pengujian keseluruhan sistem ini dilakukan sesuai dengan melakukan simulasi kondisi pada alat agar responden dapat memberikan penilaian pada kuesioner yang diberikan. Simulasi kondisi ini dilakukan karena cahaya dari luar yang diterima oleh ruangan sulit untuk dikondisikan sesuai dengan kondisi pengujian yang dilakukan. Oleh sebab itu, agar mendapatkan nilai intensitas cahaya yang diinginkan dilakukan simulasi kondisi pada alat itu sendiri dengan melakukan penutupan sensor cahaya agar nilai intensitas cahaya dapat disesuaikan dengan detail pengujian perangkat seperti pada Tabel II. Setelah dilakukan simulasi pada pengujian perangkat, kemudian dilakukan pengecekan terhadap data yang tersimpan pada sistem web. Berikut merupakan contoh data yang telah tersimpan pada sistem monitoring saklar lampu ditunjukkan Gambar 14.

TABEL VII. HASIL PENGUJIAN RELAY

\begin{tabular}{|c|c|c|c|c|}
\hline No. & $\begin{array}{c}\text { Skenario } \\
\text { Pengujian }\end{array}$ & $\begin{array}{c}\text { Hasil Yang } \\
\text { Diharapkan }\end{array}$ & $\begin{array}{c}\text { Hasil } \\
\text { Pengujian }\end{array}$ & Kesimpulan \\
\hline 1 & $\begin{array}{c}\text { Form pilih } \\
\text { bulan dan } \\
\text { tahun diisi } \\
\text { dengan } \\
\text { waktu yang } \\
\text { tidak } \\
\text { memiliki data } \\
\text { diberkas } \\
\text { penyimpanan }\end{array}$ & $\begin{array}{c}\text { Menampilkan } \\
\text { data kosong } \\
\text { pada grafik }\end{array}$ & Sesuai & Valid \\
\hline 2 & $\begin{array}{c}\text { Form pilih } \\
\text { bulan dan } \\
\text { tahun diisi } \\
\text { dengan } \\
\text { waktu yang } \\
\text { memiliki data } \\
\text { diberkas } \\
\text { penyimpanan }\end{array}$ & $\begin{array}{c}\text { Menampilkan } \\
\text { pengata } \\
\text { pada grafik }\end{array}$ & & \\
& & & \\
& & & \\
& & & \\
& & & \\
\end{tabular}

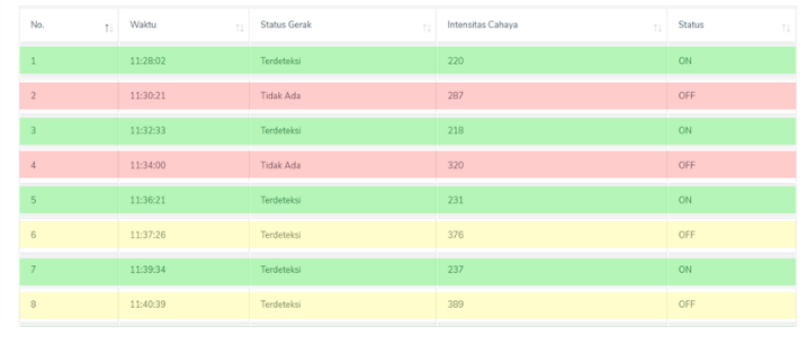

Gambar 14. Hasil pengujian fungsi keseluruhan sistem.

Gambar 14 merupakan hasil pencatatan data penggunaan lampu yang tersimpan pada sistem web. Dari gambar tersebut dapat dilihat bahwa data yang tersimpan dan keputusan yang dilakukan oleh sistem tampak sesuai dengan detail pengujian alat pada Tabel 2. Dilihat dari warna yang telah diberikan, warna hijau pada tabel tersebut merupakan keputusan yang digunakan untuk menyalakan lampu dalam kondisi nilai intensitas cahaya rendah pada ruangan dan terdapat gerakan. Kemudian warna merah merupakan keputusan untuk melakukan pemadaman lampu dalam 
kondisi tidak ada gerakan yang akan mengabaikan nilai intensitas cahaya pada ruangan. Sedangkan warna kuning merupakan keputusan dalam memadamkan lampu dalam kondisi terdapatnya gerakan pada ruangan dan nilai intensitas cahaya tinggi atau melebihi dari batas yang ditentukan. Oleh sebab itu dapat disimpulkan bahwa sistem sudah berjalan dengan baik sesuai dengan yang diharapkan. Hasil dari durasi penggunaan lampu dapat dilihat pada Gambar 15 yang disajikan dalam bentuk grafik.

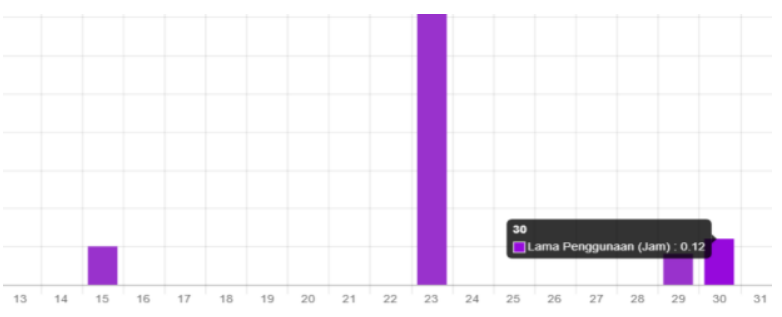

Gambar 15. Grafik lama penggunaan lampu.

Gambar 15 merupakan hasil dari pembuatan grafik dari durasi penggunaan lampu oleh sistem. Grafik ini menampilkan data tanggal berdasarkan bulan dan lama penggunaan atau hasil kalkulasi dari log lampu. Dapat dilihat pada Gambar 14 merupakan data log lampu yang kemudian data tersebut disajikan dalam bentuk grafik. Dari hasil konversi log lampu menjadi grafik, dapat disimpulkan sistem memiliki fungsional luaran yang sesuai harapan.

\section{d. Hasil Pengujian Dengan Metode Mean Opinion Score(MOS)}

Evaluasi melalui metode MOS ini ditujukan bagi responden dari mahasiswa PSTI UNRAM yang ikut serta dalam proses pengujian dengan mencoba menjalankan sistem kemudian mengisi kuesioner yang diberikan. Pengujian berfungsi mengetahui opini dari pengguna secara langsung. Adapun isi kuesioner yang diberikan adalah sebagai berikut :

1. Apakah sistem saklar lampu berbasis loT dapat berjalan dengan baik dan sesuai dengan harapan?

2. Apakah sistem monitoring pada sistem saklar lampu berbasis IoT dapat memberikan informasi mengenai intensitas cahaya, keberadaan seseorang dan status lampu di dalam ruang D1-02 PSTI UNRAM?

3. Apakah fungsi filter data grafik dan log lampu mudah dipahami dan digunakan?

4. Apakah sistem ini dapat membantu atau memudahkan manajemen penggunaan lampu di dalam ruang D1-02 PSTI UNRAM?
5. Apakah antarmuka dari sistem monitoring saklar lampu berbasis web ini mudah dipahami dan digunakan (user friendly)?

Jumlah responden yang terlibat yaitu 20 orang dengan jumlah laki-laki 6 orang dan perempuan 14 orang dan terdapat 6 orang yang menggunakan kacamata. Dengan pertimbangan bahwa penggunaan kacamata dapat mempengaruhi penglihatan seseorang. Hasil pengujian parameter MOS yang diperoleh ditunjukkan Tabel VII.

TABEL VIII. HASIL PENGUJIAN MOS

\begin{tabular}{|c|c|c|c|c|c|c|c|c|}
\hline No. & Questions & $\begin{array}{l}\text { SS } \\
\text { (5) }\end{array}$ & $\begin{array}{l}S \\
\text { (4) }\end{array}$ & $\begin{array}{l}\text { TT } \\
\text { (3) }\end{array}$ & $\begin{array}{l}\text { TS } \\
\text { (2) }\end{array}$ & $\begin{array}{l}\text { STS } \\
\text { (1) }\end{array}$ & Sum & $\begin{array}{c}\text { Mean } \\
\text { pi }\end{array}$ \\
\hline 1 & Ke-1 & 13 & 7 & - & - & - & 20 & 4.65 \\
\hline 2 & Ke-2 & 15 & 5 & - & - & - & 20 & 4.75 \\
\hline 3 & Ke-3 & 8 & 12 & - & - & - & 20 & 4.40 \\
\hline 4 & $\mathrm{Ke}-4$ & 10 & 10 & - & - & - & 20 & 4.50 \\
\hline 5 & Ke-5 & 12 & 8 & - & - & - & 20 & 4.60 \\
\hline \multicolumn{2}{|c|}{ Sub Total } & 58 & 42 & - & - & - & 100 & 22.90 \\
\hline \multicolumn{8}{|c|}{ MOS (Mean Opinion Score) } & 4.58 \\
\hline
\end{tabular}

Berikut ini merupakan rumus yang digunakan dalam menghitung skor rata-rata dari bobot nilai yang didapat [10] :

$$
\text { meanpi }=\frac{\sum S i \cdot B i}{n}
$$

Dimana :

mean $\mathrm{pi}=$ rata-rata skor setiap atribut pertanyaan

$\mathrm{Si} \quad=j u m l a h$ responden yang memilih setiap atribut jawaban

$\mathrm{Bi} \quad=$ bobot setiap atribut pertanyaan

$\mathrm{n} \quad=$ jumlah responden

Untuk mendapatkan nilai MOS (Mean Opinion Score) berdasarkan skor rata-rata yang didapat, dapat digunakan rumus berikut :

$$
M O S=\frac{\sum_{i=1}^{k} \text { meanpi }}{k}
$$

Dimana :

MOS = total skor rata-rata seluruh atribut pertanyaan

$\mathrm{k} \quad=$ jumlah atribut pertanyaan

Hasil pengujian MOS pada Tabel VIII menunjukkan bahwa nilai MOS yang diperoleh yaitu sebesar 4.58. Nilai 4.58 dari skala 5 ini menunjukkan bahwa sistem 
yang dibangun sudah baik sudah berjalan sesuai dengan apa yang diharapkan.

\section{Kesimpulan Dan Saran}

\subsection{Kesimpulan}

Kesimpulan dari hasil rancang bangun sistem pada penelitian ini dapat di deskripsikan sebagai berikut :

1. Rangkaian elektronik sistem yang dibuat sudah dapat melakukan pembacaan nilai intensitas cahaya pada ruangan dan mendeteksi keberadaan seseorang serta memutus atau menghubungkan aliran listrik menuju lampu menggunakan sensor LDR, PIR dan relay dengan mikrokontroler WeMos D1 (R2) sebagai pengendali.

2. Sistem monitoring yang dibuat sudah dapat menampilkan data intensitas cahaya, status gerakan, dan status lampu yang secara realtime didapatkan dari rangkaian elektronik sistem melalui protokol MQTT yang dapat di akses pada situs "http://ac-lamp.000webhostapp.com/".

3. Berdasarkan skema pengujian yang dilakukan, sistem yang dibuat sudah dapat melakukan manajemen lampu secara otomatis berdasarkan kondisi yang diterima dan juga sistem monitoring memberikan informasi kepada pengguna dengan baik.

4. Pengujian sensor PIR pada ruang D1-02 dengan lebar 7 meter dan panjang 11 meter dapat mendeteksi keberadaan seseorang dengan jarak optimal 5 meter dengan sudut yang dapat dijangkau yaitu $60^{\circ}$ sehingga untuk ruangan tersebut dibutuhkan minimal 2 sensor PIR agar seluruh sudut ruangan dapat terjangkau.

5. Dari pengujian MOS yang telah dilakukan diperoleh nilai sebesar 4.58 dari skala 5 yang menunjukkan bahwa sistem telah layak digunakan dan termasuk dalam kategori sangat baik.

\subsection{Saran}

Jika dilakukan penelitian lebih lanjut tentang penelitian ini dapat mempertimbangkan saran - saran sebagai berikut :

1. Diharapkan sistem ini ke depannya dapat melakukan perhitungan jumlah penggunaan daya dari data yang disimpan oleh alat pada sistem web agar dapat mengetahui detail penggunaan daya oleh lampu pada ruangan.
2. Diharapkan ke depannya alat pada sistem ini diberi penambahan beberapa sensor PIR dan LDR agar dapat menjangkau seluruh sudut ruangan dalam mendeteksi keberadaan seseorang dan melakukan pembacaan nilai intensitas cahaya dengan baik.

\section{DAFTAR PUSTAKA}

[1] Iyuditya and E. Dayanti, "Sistem Pengendali Lampu Ruangan Secara Otomatis Menggunakan PC Berbasis Mikrokontroler Arduino Uno," J. Online ICT STMIK IKMI, vol. 10, no. 2, pp. 1-7, 2013.

[2] T. Budioko, "Sistem Monitoring Suhu Jarak Jauh Berbasis Internet of Things Menggunakan Protokol MQTT," Semin. Nas. Ris. Teknol. Inf., vol. 1, no. 30 July, pp. 353-358, 2016.

[3] Y. Efendi, "Internet of Things (IoT) Sistem Pengendalian Lampu Menggunakan Raspberry Pi Berbasis Mobile," J. IIm. IImu Komput., vol. 4, no. 1, pp. 19-26, 2018.

[4] N. F. Azzahra, "Rancang Bangun Purwarupa loT (Internet of Things) Kendali Lampu Dengan Protokol MQTT Pada Studi Kasus Skala Rumah Tangga," J. IIm. Ilmu-ilmu Tek., vol. 3, pp. 1-4, 2018.

[5] I. Marzuki, "Perancangan dan Pembuatan Sistem Penyalaan Lampu Otomatis Dalam Ruangan Berbasis Arduino Menggunakan Sensor Gerak dan Sensor Cahaya," Penelit. Ilmu Tek. dan Terap., vol. 10, pp. 9-16, 2019.

[6] A. K. Tsauqi et al., "Saklar Otomatis Berbasis Light Dependent Resistor (LDR) Pada Mikrokontroler Arduino Uno," Pros. Semin. Nas. Fis., vol. 5, no. Seminar Nasional Fisika SNF2016, pp. 19-24, 2016.

[7] S. Andy and B. Rahardjo, "Keamanan Komunikasi Pada Protokol MQTT untuk Perangkat IoT," Semin. Nas. Tek. Elektro 2016, no. 10, pp. 176-184, 2016.

[8] J. Welman, "Prototype Penerangan Rumah Otomatis Berbasis Mikrokontroler ATMega8535," Universitas Islam Negeri Suska Riau, 2013.

[9] M. Pamungkas, Hafiddudin, and Y. S. Rohmah, "Perancangan dan Realisasi Alat Pengukur Intensitas Cahaya," J. Elkomika, vol. 3, no. 2, pp. 120-132, 2015.

[10] R. Fitriyanti, Lindawati, and A. Aryanti, "Studi Literatur Mean Opinion Score Menggunakan Moving Picture Quality Metrics (MPQM) Di Jaringan LTE," Semin. Nas. Inov. dan Apl. Teknol. di Ind. 2018 Tema A - Penelit., vol. 4, no. 2, pp. 10-14, 2018. 


\title{
SISTEM PAKAR DIAGNOSIS PENYAKIT TANAMAN CABAI DENGAN METODE FORWARD CHAINING DAN DEMPSTER SHAFER
}

\author{
(Expert System With Forward Chaining and Dempster Shafer Method for Diagnosis \\ of Chili Plants Diseases)
}

\author{
Mega Laely ${ }^{*}$ I Gede Pasek Suta Wijaya, Arik Aranta \\ Program Studi Teknik Informatika, Fakultas Teknik, Universitas Mataram \\ JI. Majapahit 62, Mataram, Lombok NTB, INDONESIA \\ Email:megalaily295@gmail.com, [gpsutawijaya, arikaranta]@unram.ac.id
}

\begin{abstract}
Chili plant (Capsicum Annum) is one of the horticultural commodities whose fruit has a high nutritional value, especially vitamin $A$ and $C$ content. Nationally, the productivity and harvested area of chilies are the highest compared to other horticultural commodities. One of the problems in chili plants is the attack of chili disease which can reduce the quality and quantity of chili production. This study aims to develop an expert system for diagnosis of chili plant diseases based on the knowledge of three experts using seven chili disease data and 32 symptom data. This study uses four testing techniques, namely black box testing with results that are functional in accordance with the design, testing with "theoretical calculations" in two case examples producing accurate calculation results with system calculation results, the system accuracy tester is $96.67 \%$ in the First Expert who tested 30 cases, the Mean Opinion Score (MOS) test results in a MOS score of 4.35 for Informatics Engineering students, 4.00 for Agriculture students, 4.68 for Agricultural Instructors, and 4.54 for farmers which is categorized into good system.
\end{abstract}

Keywords: expert system, chili, chili disease, Forward Chaining, Dempster Shafer

*Penulis Korespondensi

\section{Pendahuluan}

Tanaman cabai (Capsicum annum) termasuk dalam komoditi hortikultura yang buahnya memilki kandungan gizi cukup tinggi terutama kandungan vitamin A dan C. Penggunaan cabai yang cukup luas baik dalam bentuk segar maupun olahan menyebabkan komoditi ini memiliki nilai ekonomi tinggi. Nilai ekonomi yang tinggi menjadi alasan petani untuk terus membudidayakan tanaman cabai sebagai mata pencarian dalam memenuhi kebutuhan hidup [1].

Jenis cabai yang digunakan pada penelitian ini adalah cabai rawit. Menurut laporan Badan Pusat Statistika (BPS) tahun 2018, produktivitas cabai rawit di Indonesia dari tahun 2013-2018 selalu mengalami kenaikan, dengan hasil produksi pada tahun 2013 mencapai 721 ribu ton dan luas panen 125.1 ribu $\mathrm{Ha}$ meingkat menjadi 1,34 juta ton dan luas panen 172.8 ribu Ha pada tahun 2018[2]. Nusa Tenggara Barat (NTB) adalah provinsi dengan hasil produksi cabai rawit terbesar kedua di Indonesia[2]. Menurut laporan BPS (NTB) tahun 2018 hasil produksi cabai rawit pada tahun 2018 mencapai 211 ribu ton dengan luas panen 8.2 ribu Ha dan meningkat sebesar 34.16 persen dibandingkan produksi tahun 2017 yang hanya mencapai 152 ribu ton dengan luas panen $8.0 \mathrm{Ha}$ [3].

Luas panen cabai rawit menurut data terakhir 2018 berada pada peringkat pertama dalam komoditi hortikultura dengan luas 7,7 ton/hektar [2]. Angka tersebut belum mencapai potensi hasilnya yang berkisar antara 12-20 ton/hektar [4]. Perkembangan produksi cabai dapat dipengaruhi oleh beberapa kendala yaitu, kendala dari segi agronomi dan pemasaran yang dapat menurunkan produksi dan pendapatan petani . Contoh dari segi agronomi yaitu adanya Organisme Pengganggu Tanaman (OPT) pada tanaman cabai [1].

Organisme pengganggu tanaman yang dapat menyerang tanaman cabai mulai dari tahap persemaian hingga panen. Salah satu contoh yaitu patogen yang merupakan cikal bakal dari penyakit pada tanaman cabai [4]. Terbatasnya jumlah penyuluh yang menyebabkan kegiatan penyuluhan terkait budidaya tanaman cabai dan penanggulan penyakit tanaman cabai terhadap petani yang mengakibatkan 